\title{
Modified micro suction cup/ rhizobox approach for the in- situ detection of organic acids in rhizosphere soil solution
}

\author{
Journal Article \\ Author(s): \\ Dessureault-Rompré, Jacynthe; Nowack, Bernd; Schulin, R.; Luster, Joerg \\ Publication date: \\ 2006 \\ Permanent link: \\ https://doi.org/10.3929/ethz-b-000024921
}

Rights / license:

In Copyright - Non-Commercial Use Permitted

Originally published in:

Plant and Soil 286(1-2), https://doi.org/10.1007/s11104-006-9029-z 


\title{
Modified micro suction cup/rhizobox approach for the in-situ detection of organic acids in rhizosphere soil solution
}

\author{
Jacynthe Dessureault-Rompré · Bernd Nowack • \\ Rainer Schulin · Jörg Luster
}

Received: 10 January 2006/ Accepted: 6 May 2006/Published online: 26 July 2006

(C) Springer Science+Business Media B.V. 2006

\begin{abstract}
Root-soil interactions can strongly influence the soil solution chemistry in the rhizosphere. In the present study we propose a modification of the classical rhizobox/micro suction cup system to make it suitable for the collection and analysis of organic acids in the rhizosphere. In order to show the potential of the method, we tested the modified system with Lupinus albus L. as a model plant known to exude large amounts of citrate. The suction cups were installed through the transparent front plate of the rhizoboxes just after the emergence of cluster roots in order to allow optimal localized collection of soil solution. A small dead-volume allowed almost immediate stabilisation with formaldehyde of the sampled soil solutions in the collection container to prevent microbial degradation. The concentrations of organic acids were significantly larger in the rhizosphere soil solution of active cluster roots of Lupinus albus L. than in the bulk soil solution (about $400 \mu \mathrm{M}$ of citrate
\end{abstract}

J. Dessureault-Rompré · B. Nowack $(\bowtie) \cdot R$. Schulin Institute of Terrestrial Ecology, ETH Zürich, Universitätstrasse 16, 8092 Zürich, Switzerland e-mail: nowack@env.ethz.ch

\section{J. Luster}

Swiss Federal Institute for Forest, Snow, and Landscape Research (WSL), CH-8903 Birmensdorf, Switzerland versus $<0.05 \mu \mathrm{M})$. We were able to follow the exudation process in-situ, which occurred during 2-3 days. Also the concentrations of other organic acids and inorganic anions differed between the bulk soil and the rhizosphere of cluster roots, normal roots, and nodules.

Keywords Cluster roots $\cdot$ Lupinus albus $\cdot$ Micro suction cups $\cdot$ Rhizobox $\cdot$ Root exudates $\cdot$ Soil solution

\section{Introduction}

Active plant roots have been recognized to influence soil solution chemistry in their vicinity (Marschner 1995). This rhizosphere differs in many aspects from the bulk soil due to root activity and higher microbial and fungal activities. Root exudation of low-molecular weight organic acids has been found to play an important role in the mobilisation and uptake of nutrients as well as the detoxification of harmful substances (Jones 1998; Marschner 1995; Ryan et al. 2001). Most of our knowledge on the exudation of organic acids stems from studies in hydroponic systems (e.g., Neumann et al. 1999; Watt and Evans 1999) or soil extracts (e.g., Dinkelaker et al. 1989; Gerke et al. 1994; Jones and Darrah 1994; Li et al. 1997). However, roots in hydroponic systems can behave 
differently compared to natural conditions in soils (Marschner 1995). Very little is known about the behavior of organic acids in soil solution in terms of mobility and degradability. Thus, there is a large need for in-situ studies in soils.

The use of micro-techniques for the collection of soil solution enables non-destructive in-situ observation of soil solution chemistry at high spatial and temporal resolution (Grossmann and Udluft 1991). By contrast, obtaining the soil solution by soil sampling followed by centrifugation or by extraction with water or salt solution is operationally strongly biased, and, because sampling is destructive, does not allow for time studies (Wolt 1994). Soil solution investigations at the microscale started in the 1990s with the miniaturization of the sampling probes (Göttlein et al. 1996; Vetterlein and Marschner 1993; Vetterlein et al. 1993). Later, micro suction cups were used in conjunction with rhizotrones, also called rhizoboxes, that allow observing the development of root systems through a transparent front plate (Dieffenbach et al. 1997). This approach allowed for the first time to monitor the soil solution chemistry with high spatial resolution for rhizosphere studies without destroying the soil structure. This technique has been used to study aluminium and nutrient chemistry in the rhizosphere in the laboratory (Arocena et al. 2004; Göttlein et al. 1999; Wang et al. 2004) as well as in the field (Braun et al. 2001; Göttlein and Matzner 1997; Hagedorn et al. 1999). However, there are only a few in-situ studies of organic acids in soil solution. Concentrations of organic acids in forest floor leachates collected by means of zero-tension lysimeters were found to be between 1 and $50 \mu \mathrm{M}$ (Krzyszowska et al. 1996; Strobel 2001). Sandnes et al. (2005) observed low concentrations of organic acids $(<1-80 \mu \mathrm{M}$ for di- and tri-carboxylic acids) in a study comparing samples collected from rhizoboxes and microcosms planted with birch and spruce with samples from root windows installed in the field in the root zone of these trees. The rhizobox study showed higher concentrations of organic acids, which was related to a higher root and fungal density and activity. No comparison between rhizosphere and bulk soil solution and no stabilisation of the samples was done in this study.
The objective of this study was to test a modification of the classical rhizobox micro suction cup system design to obtain a better precision of the localized in-situ sampling of soil solution and, in addition, to minimize the risk of biodegradation in the sample. We chose Lupinus albus L. as a test plant because it is well known to exude high amounts of citrate into the rhizosphere by using special roots called cluster roots to cope with phosphate deficiency (Dinkelaker et al. 1995).

\section{Material and methods}

\section{Rhizobox}

The rhizobox used in this study was adapted from the one introduced by Dieffenbach et al. (1997). Each box had a length of $60 \mathrm{~cm}$, a width of $15 \mathrm{~cm}$ and a depth of $1 \mathrm{~cm}$ in the main rooting compartment (inner volume around $900 \mathrm{~cm}^{3}$ ). Only one seedling was planted per box. The front side of the rhizobox was covered with a transparent plate made from acrylic glass to allow visual observation of the development of the roots. The three other sides of the rhizobox were made from dark polyvinylchloride (PVC). The rhizobox was positioned at an angle of $30^{\circ}$ to force the roots to grow along the transparent plate. The transparent side of the rhizobox was covered with a dark cardboard box to prevent light interference on root growth. The cardboard was removed only to observe the root development and to take samples. Seeds of Lupinus albus L. ("Weissblühende Tellerlupine" cultivar, Ufa AG, Switzerland) were pre-treated with $10 \%$ hydrogen peroxide (Liang and $\mathrm{Li} 2003$ ) and then germinated in black garden soil for 1 week. Healthy plants were gently washed with deionised water to remove the organic black soil and transplanted into the rhizoboxes. We used a weakly acid loam from the top $20 \mathrm{~cm}$ of a Luvisol near Birr (Switzerland, $\mathrm{pH}$ $6.4\left(0.01 \mathrm{M} \mathrm{CaCl}_{2}\right), 15.1 \mathrm{~g} / \mathrm{kg} \mathrm{C}$ org, $1.5 \mathrm{~g} / \mathrm{kg} \mathrm{N}$ tot $49 \mathrm{mg} / \mathrm{kg} \mathrm{P} \mathrm{P}_{\text {available }}$ (Kuo 1996), $862 \mathrm{mg} / \mathrm{kg} \mathrm{P} \mathrm{P}_{\text {org }}$ (Kuo 1996), 36\% sand, $49 \%$ silt, $15 \%$ clay). The soil was air dried, sieved $(2 \mathrm{~mm})$ and filled into the rhizoboxes at a bulk density of about $1.2 \mathrm{~g} \mathrm{~cm}^{-3}$. 
The rhizobox experiment was conducted under controlled conditions in a climate chamber (light $16 \mathrm{~h}$ with an intensity at canopy height of $150 \mu \mathrm{mol} \mathrm{m} \mathrm{m}^{-2}, \quad 80 \%$ humidity, temperature day/night: $20 / 16^{\circ} \mathrm{C}$ ). The boxes were irrigated with synthetic rain water (ionic composition in $\mu \mathrm{M}$ : $70 \mathrm{NH}_{4}, 70 \mathrm{NO}_{3}, 3.2 \mathrm{PO}_{4}, 17 \mathrm{Cl}, 3.1 \mathrm{SO}_{4}$, $4.3 \mathrm{Na}, 7.7 \mathrm{~K}, 5 \mathrm{Ca}, 1.3 \mathrm{Mg}, 0.15 \mathrm{Zn}, \mathrm{pH}=5.5$ ) using wicks that were made from a polyether sulfone hollow fiber (Rhizon irrigators, Rhizosphere research products, Wageningen The Netherlands) and installed at 5, 30 and $55 \mathrm{~cm}$ soil depth. A water potential of $-40 \mathrm{hPa}$ was applied by means of a hanging water column between the wicks and the reservoir.

\section{Soil solution sampling}

Samples were taken through the transparent front plate of the rhizoboxes and not from the back side (Fig. 1) as in the original design by Dieffenbach et al. (1997). This modification was made because in the rhizobox root growth is not necessarily restricted to the soil close to the front plate. Some roots can also grow along the backside of the box despite the $30^{\circ}$ inclination of the boxes. The conventional way of installing the micro suction cups through the back side of the rhizobox does not allow to determine with certainty whether a sample represents rhizosphere or bulk soil solution. Installation of the cups through the transparent front plate assures that the "active length" of the micro suction cup of $5 \mathrm{~mm}$ is near the root

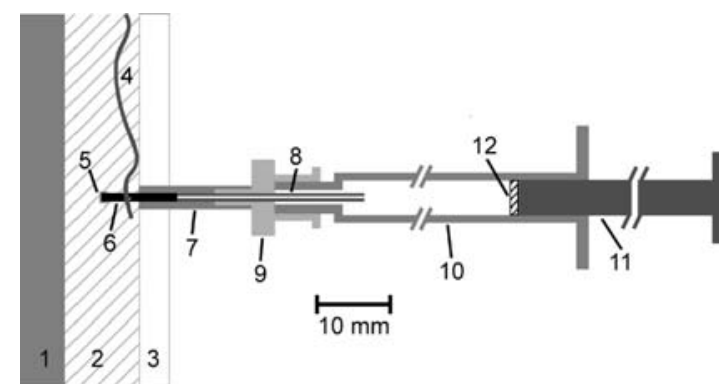

Fig. 1 Scheme of the soil solution sampling: (1) back of rhizobox, (2) soil, (3) transparent front plate, (4) root, (5) hot glue, (6) ceramic capillary, (7) outer tubing, (8) insert tubing, (9) female luer connector, (10) $1 \mathrm{ml}$ syringe, (11) piston in open position to produce vacuum, (12) formaldehyde of interest. To optimise the precise positioning of the suction cups, holes were drilled through the front plate at a given location well defined in terms of distance to a root just before insertion of the cups by using a hand drill. In order to sample the rhizosphere soil solution around cluster roots, the emergence of the rootlets was the starting point of sampling. Each cluster root was sampled for a period of 7-10 days, once a day for a period of $8 \mathrm{~h}$. The sampling-free time of $16 \mathrm{~h}$ accounts for the need of the soil to reequilibrate, because each time soil solution is sampled, water is removed from the sampling site and the conditions for water and nutrient chemistry are changed (Vetterlein and Jahn 2004). Micro suction cups were positioned around the cluster root at three different distances to get spatial information. The three layers of micro suction cups ( $<1 \mathrm{~mm}$ from the rootlet apex, $1-5 \mathrm{~mm}$ and 6-10 mm) were installed in such a way that the interaction between the individual cups was minimised. One millilitre syringes (Norm-Ject, Henke Sass Wolf, Tuttlingen Germany) connected to the micro suction cups were used to collect the soil solution (Fig. 1). About $20 \mu \mathrm{l}$ of formaldehyde solution ( $>36.5 \%$ in water (Fluka)) were added to each syringe before the sampling to prevent microbial modification of the collected samples. In order to verify the ability of formaldehyde to keep the soil solution composition constant we analyzed different samples from 9 to 54 days after the first analysis. The concentrations of inorganic anions and organic acids did not change significantly over time $(3.5 \%$ change in average within 54 days) thus proving the efficiency of the formaldehyde. Vacuum was applied once by pulling the piston of the syringe to its end position. With the type of syringe used, the piston remained at this position for the whole sampling period without or little fixing using adhesive tape.

Ceramic capillaries (pure aluminium oxide produced by Pl ceramic, D-07589 Lederhose Germany) were used as micro suction cup materials (Göttlein et al. 1996). Pieces of $1 \mathrm{~cm}$ length were connected to Tygon tubes (R3607 $0.89 \mathrm{~mm}$ (ID), $0.86 \mathrm{~mm}$ (wall thickness), (Ismatec, Glattbrugg, Switzerland)) and to a female luer connector (Fig. 1). A smaller PTFE tube (Tube 13902267 $1 / 32 \times 0.25 \mathrm{~mm} \quad$ (OmniLab, Mettmenstetten 
Switzerland)) was inserted into the Tygon tube to reduce the total dead volume to $4 \mu$ l. The tips of the capillaries were closed with hot glue (Pattex transparent sticks, Henkel, Germany). Each micro suction cup was tested for leaks. Different to the usual conditioning, the micro suction cups were first sterilized with ethanol. Also, to minimise adsorption of metals onto the suction cup materials, they were conditioned by passing up to $10 \mathrm{ml}$ of autoclaved soil solution obtained by a batch soil water extract (soil/water ratio 1/10). Adsorption of low-molecular weight organic acids (Sandnes et al. 2005) or DOC around neutral pH (Rais et al. 2006) on these ceramic capillaries was reported to be negligible.

\section{Soil solution analysis}

For each soil solution sample, the sampling volume was recorded. The samples were analyzed for low molecular weight organic acids (LMWOA) (citrate, malate, oxalate, formate, acetate) and inorganic anions (sulfate, nitrate, and phosphate) using ion chromatography (Dionex autosampler system, AS 50 column, eluent generator: potassium hydroxide $(1-60 \mathrm{mM})$, flow: $1.5 \mathrm{ml} \mathrm{min}^{-1}$ ) with $200 \mu \mathrm{l}$ insert glass vials to reduce the sample volume. The $\mathrm{pH}$ was measured by an ion sensitive field effect transistor electrode (ISFET sensor, Sentron, Roden The Netherlands). For the cluster roots, the sampling period was divided into the three sub periods "before", "during" and "after" LMWOA exudation. "During" was defined as the period during which the concentration of citrate was increased 10times above the background. During the experiment, 5 cluster roots were sampled. The soil solution in the rhizosphere of normal roots (along long roots and near lateral roots) and nodules as well as in the bulk soil $(>2 \mathrm{~cm}$ from the nearest root) was also sampled. Statistical differences were tested using Student's $t$-test (Systat 11). Pearson correlation coefficients between the sampling volume and concentrations of organic acids and inorganic anions were calculated using Systat 11.

The formaldehyde added to prevent microbial degradation contains some impurities, mainly formate, acetate, and chloride with traces of some cations ( $\mathrm{Al}, \mathrm{Mn}$, and $\mathrm{Pb})$. For a soil solution sample of $400 \mu$ these impurities correspond to a concentration of $150 \mu \mathrm{M}$ formate, $28 \mu \mathrm{M}$ acetate, and $5.4 \mu \mathrm{M}$ chloride. Formaldehyde solution can also affect the $\mathrm{pH}$ measurement at small sampling volumes. Titration curves with formaldehyde were measured on soil water extracts to quantify this influence of formaldehyde on soil solution $\mathrm{pH}$. All presented data were corrected for these contaminations of ions and the $\mathrm{pH}$ influence.

\section{Results}

Sampling volume

The average sample volume of soil solution collected in the vicinity of cluster roots was $300 \pm 100 \mu \mathrm{l}$ for a distance of less than $1 \mathrm{~mm}$ from the root, $450 \pm 150 \mu$ l between 1 and $5 \mathrm{~mm}$ from the root, $500 \pm 150 \mu \mathrm{l}$ between 6 and $10 \mathrm{~mm}$ from the root, and $600 \pm 100 \mu \mathrm{l}$ in the bulk soil. This decrease towards the roots reflected the influence of root water uptake on the water content of the soil.

Overall, sampling volume and concentrations of organic acid and inorganic anions did not reveal any significant relationship. The Pearson $r$ correlation coefficients were between -0.016 and -0.27 . Figure $2 \mathrm{a}$ shows that nitrate concentrations were indeed independent of the sampling volumes. On the other hand, we found a trend to higher concentrations of organic acids such as citrate at smaller sampling volumes (Fig. 2b). Since the sampling volume, however, was also correlated with the distance to the nearest roots, as is shown above, the highest concentrations of citrate were found close to the root.

Temporal variations of citrate in the rhizosphere of cluster roots

The release of substances from the roots to the rhizosphere refers to an exudation process. In the case of the cluster roots of white lupin, the exudation of organic acids will occur only during a limited period because of their restricted lifetime (Watt and Evans 1999). Figure 3 shows the variation in citrate concentration of the 
rhizosphere solution of one cluster root over 11 days. For a period of 3-4 days, the citrate concentration in the region close to the cluster root quickly reached a maximum of sometimes up to $2 \mathrm{mM}$ and then decreased again as rapidly as it rose.

During the exudation of citrate the $\mathrm{pH}$ of the rhizosphere soil solution dropped in average from 6.9 to 5.4 (Table 1). Figure 3 shows an example in which the $\mathrm{pH}$ around a single cluster root dropped from about 8 to 5.5 during exudation and
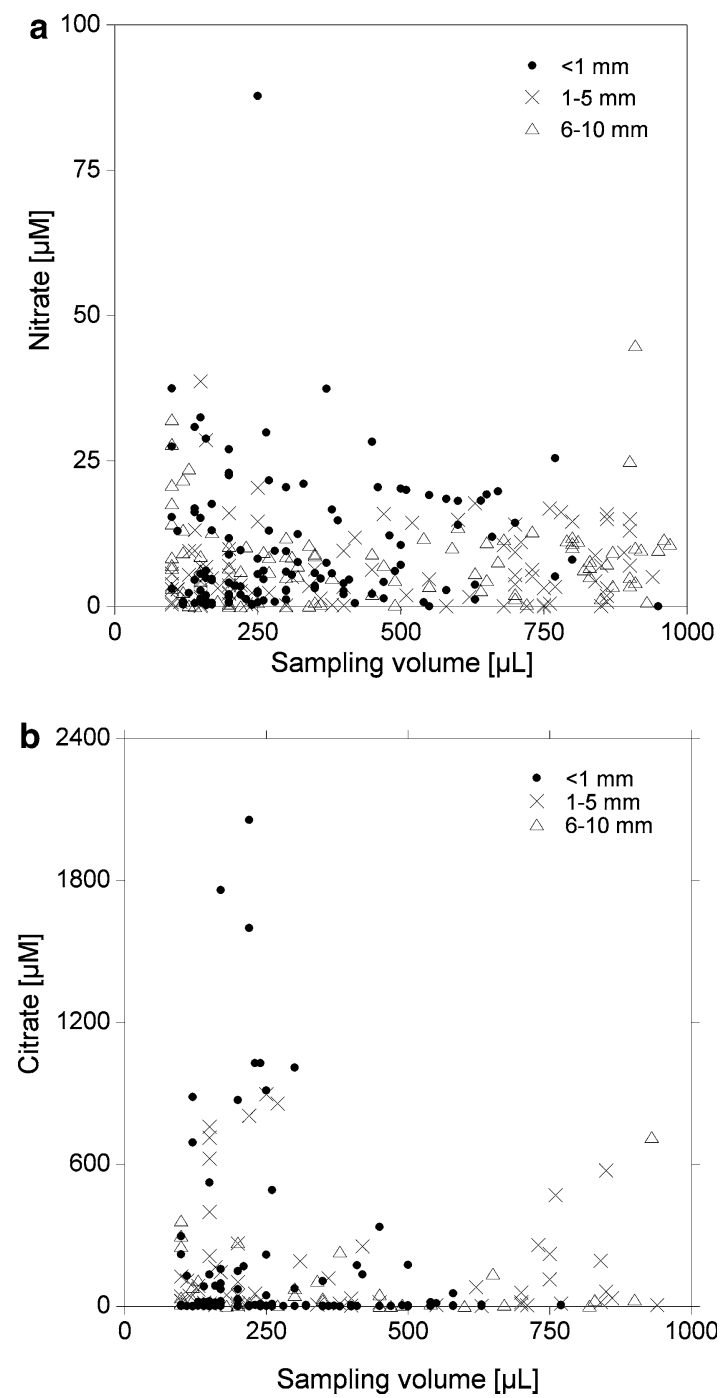

Fig. 2 Relationship between sampling volume and concentration of nitrate (a) and citrate (b) in the rhizosphere of white lupin at different distances from cluster roots remained at the lower value for the rest of the sampling period.

Comparison between rhizosphere and bulk soil solution

The composition of the soil solution samples differed strongly between the rhizosphere of white lupin cluster roots and bulk soil (Table 1). The concentrations of citrate and malate were significantly higher near cluster roots than in the bulk soil. In contrast to the other organic acid anions, these two compounds were measured exclusively during the restricted time of exudation. The wide range of organic acid concentrations found in the vicinity of the cluster roots can be attributed to the exudation processes itself and the way we divided the sampling period into the three sub periods. The class "during exudation" also includes those data from the beginning and the end of the exudation process with small concentrations. Considering that the maximum values during the exudative burst were generally high and could reach up to $2 \mathrm{mM}$, this has resulted in the very wide range of concentrations reported in Table 1.

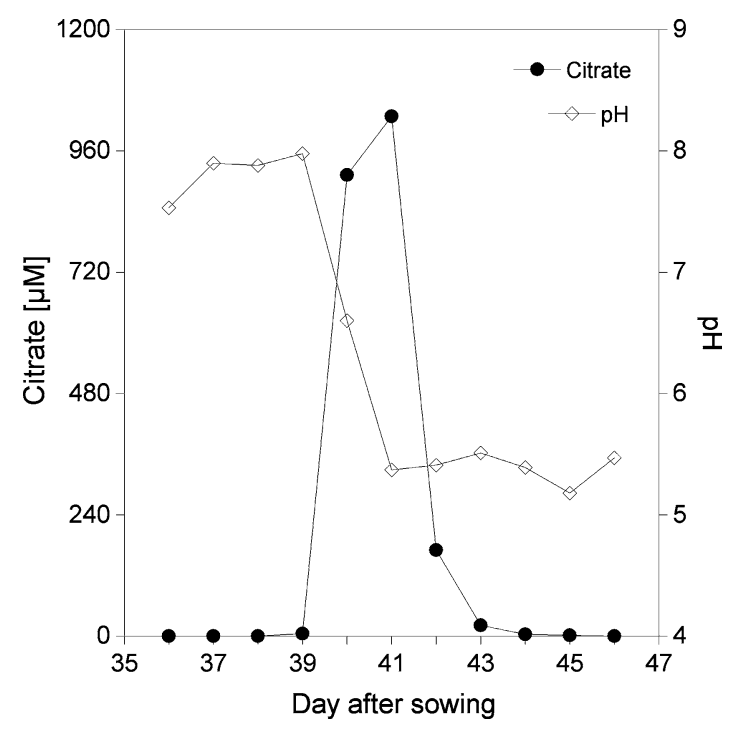

Fig. 3 Temporal variation of citrate concentration and $\mathrm{pH}$ in the rhizosphere ( $<1 \mathrm{~mm}$ from cluster roots) of white lupin over 11 days. The presented results are for one single cluster root 


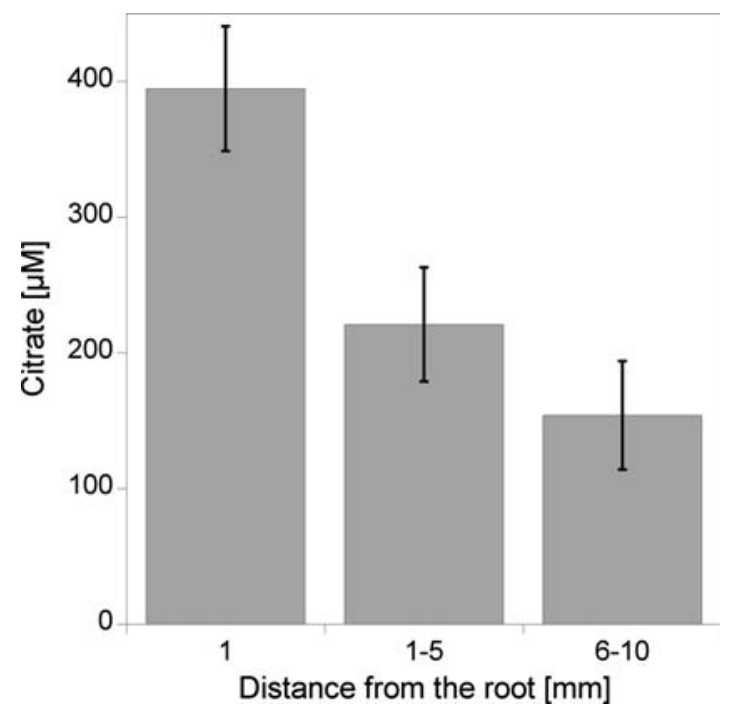

Fig. 4 Average concentration ( \pm standard error) of citrate at different distances from 5 cluster roots during the exudation event

Also, the concentrations of acetate and oxalate were significantly higher in the cluster root rhizosphere during the exudation. But low concentrations of these two acids were also found in almost all other samples. Acetate and oxalate were also higher near the nodules than in the vicinity of normal roots and in the bulk soil. Although the number of samples was relatively small, it is very likely that the high acetate and oxalate concentrations near the nodules were related to the microbial activity in this symbiosis between plant and rhizobia.

Lower concentrations of nitrate and phosphate were found near the cluster roots compared to the bulk soil and, in addition, were smaller after than before and during the exudation burst. No difference between bulk soil and cluster root rhizosphere was found for sulfate. The rhizosphere $\mathrm{pH}$ of cluster root soil solution decreased following exudation and reached its lowest value measured in our experiment (Table 1).

Figure 4 shows the average spatial distribution of citrate around 5 cluster roots during the exudation burst. We observed a decrease in citrate concentrations with increasing distance from the cluster root. The concentrations at $1 \mathrm{~mm}$ distance from the root were higher than at greater distance.

\section{Discussion}

Sampling, zone of influence

Let us consider that a sampling volume of 300 and $500 \mu \mathrm{l}$ corresponds to a sampled soil volume of about 600 and $1000 \mu \mathrm{l}$, respectively, or a sampled soil cylinder around the suction cup with a diameter of about 1.2 or $1.6 \mathrm{~cm}$, respectively. Then, the chemical composition of the samples represents about the average soil solution in this zone of influence. It thus consists of "true" rhizosphere soil solution in equilibrium with rhizosphere soil and roots but also soil solution that was transported from the bulk soil to the suction cup. If this soil compartment contains roots, these roots are "flushed" by the passing soil solution and exuded compounds are transported to the suction cup. The larger the sampling volume, the larger this influence becomes. Very small sample volumes on the other hand, allow for only a very restricted number of analyses and require very sensitive analytical methods (Puschenreiter et al. 2005). High sampling rates as in our experiment are not only disadvantageous. First of all, the chosen water tension allowed for a good growth of lupin in the soil that was used in this study. Furthermore, sufficient sample volume for the various chemical analyses could be collected in a relatively short time period. Short sampling periods allow for high temporal resolution, e.g., for assessing diurnal exudation cycles.

Considering the different relationships between sampling volume and concentration of nitrate and citrate, respectively, at different distances from cluster roots, we conclude that gradients in ion concentrations can effectively be related to root influence and that dilution effects can be neglected. However it is important to keep in mind that the sampling volume is very much dependent on the soil conditions surrounding the sampling site. In natural soils these conditions can be very heterogeneous and are partly responsible for the differences observed between different sampling sites. In our rhizobox system with a well mixed soil, however, this influence can be neglected.

The rhizosphere effect on soil solution concentration is limited in space. With increasing 
distance from the root system, the organic acid concentrations decrease and the inorganic anion concentrations (e.g., phosphate or nitrate) increase until they reach the bulk soil level. The observed decrease of citrate with distance from the cluster root does not represent, however, the equilibrium soil solution composition in the respective distance from the roots, but about the average concentrations of citrate within the zone of influence of the suction cups as discussed above. On the other hand, for the group of suction cups at a distance of $6-10 \mathrm{~mm}$, for which the roots are just at the rim of the zone of influence, the citrate concentrations are still about one third of what is measured at a distance of $<1 \mathrm{~mm}$. This indicates migration, either by diffusion or mass flow during sampling of exuded citrate away from the immediate vicinity of the rootlet apex, despite consumption by microorganisms and adsorption to soil matrix components.

In-situ detection of exudation by white lupin

In good agreement with results from hydroponic studies (Dinkelaker et al. 1989; Gerke et al. 1994; Neumann et al. 2000) we observed that citrate and malate are exuded by cluster roots of white lupin. Moreover, the time course of the citrate exudation observed in our experiment is consistent with results from hydroponic cultures (Hagström et al. 2001; Skene 2003; Watt and Evans 1999). The rapid decrease of citrate following the exudative burst could be explained by microbial consumption, spatial diffusion in soil solution or sorption to soil matrix components (Jones 1998; Jones et al. 2003).

Elevated microbial activity in the root zone probably contributed to the higher oxalate and acetate concentrations in the rhizosphere, because microbes are responsible for the production of a wide range of organic acids especially in situations where nutrients are limited (Rozycki and Strzelczyk 1986).

Root exudation of organic acids has been found to play an important role in the mobilisation and uptake of nutrients (Jones 1998; Marschner 1995; Ryan et al. 2001). Release of organic acids as well as acidification of the rhizosphere have been found to affect the availability and uptake of 
mineral nutrients. This acidification can either be caused directly by the release of organic acids (Marschner 1995) or by concomitant $\mathrm{H}^{+}$-release (Jones 1998). There is ample evidence of water soluble $\mathrm{P}$ depletion occurring in the vicinity of roots (Morel and Hinsinger 1999). In addition, exchangeable phosphate liberated by exuded citrate is taken up at once. Furthermore nitrate is rapidly taken up in the rhizosphere due to the high demand for this essential macronutrient in plant nutrition (Jungk 2002). As a difference, sulfate is only taken up by plants at a low rate (Marschner 1995).

To conclude, we demonstrated that with our modified rhizobox micro suction cup system we were able to detect in-situ organic acids exuded from roots and to follow temporally an exudation process and its effect on soil solution chemistry. With this system we could also detect differences between bulk soil, rhizosphere of cluster roots, and rhizosphere of other roots (e.g., nodules). Moreover, to our best knowledge, this is the first time that the exudation of organic acids by white lupin has been shown in-situ in soil solution. Based on our results, the system is a good choice to study strong root exudation by single roots in-situ.

Acknowledgements This work was supported by project C02.0084, State Secretariat for Research and Education, Switzerland, within COST Action 631 (Understanding and Modelling Plant-Soil Interactions In the Rhizosphere Environment) and the Fond Québécois de la Recherche sur la Nature et les Technologies. The rhizoboxes were designed and produced by Arthur Kölliker, WSL.

\section{References}

Arocena JM, Göttlein A, Raidl S (2004) Spatial changes of soil solution and mineral composition in the rhizosphere of Norway-spruce seedlings colonized by Piloderma croceum. J Plant Nutr Soil Sci 67:479-486

Braun M, Dieffenbach A, Matzner E (2001) Soil solution chemistry in the rhizosphere of beech (Fagus silvatica L.) roots as influenced by ammonium supply. J Plant Nutr Soil Sci 164:271-277

Dieffenbach A, Göttlein A, Matzner E (1997) In-situ soil solution chemistry in an acid forest soil as influenced by growing roots of Norway spruce (Picea abies [L.] Karst.). Plant Soil 192:57-61

Dinkelaker B, Hengeler C, Marschner H (1995) Distribution and function of proteoid roots and other root clusters. Bot Acta 108:183-200
Dinkelaker B, Römheld V, Marschner H (1989) Citric acid excretion and precipitation of calcium in the rhizosphere of white lupin (Lupinus albus L.). Plant Cell Environ 12:285-292

Gerke J, Römer W, Jungk A (1994) The excretion of citric and malic acid by proteoid roots of Lupinus albus L.; effects on soil solution concentrations of phosphate, iron, and aluminium in the proteoid rhizosphere in samples of an oxisol and luvisol. J Plant Nutr Soil Sci 157:289-294

Göttlein A, Heim A, Matzner E (1999) Mobilization of aluminium in the rhizosphere soil solution of growing tree roots in an acidic soil. Plant Soil 211:41-49

Göttlein A, Hell U, Blasek R (1996) A system for microscale tensiometry and lysimetry. Geoderma 69:147-156

Göttlein A, Matzner E (1997) Microscale heterogeneity of acidity related stress-parameters in the soil solution of a forested cambic podzol. Plant Soil 192:95-105

Grossmann J, Udluft P (1991) The extraction of soil water by suction-cup method: a review. J Soil Sci 42:83-93

Hagedorn F, Mohn J, Schleppi P, Flühler H (1999) The role of rapid flow paths for nitrogen transformation in a forest soil: A field study with micro suction cups. Soil Sci Soc Am J 63:1915-1923

Hagström J, James WM, Skene KR (2001) A comparison of structure, development and function in cluster roots of Lupinus albus L. under phosphate and iron stress. Plant Soil 232:81-90

Jones DL (1998) Organic acids in the rhizosphere-a critical review. Plant Soil 205:25-44

Jones DL, Darrah PR (1994) Role of root derived organic acids in the mobilization of nutrients from the rhizosphere. Plant Soil 166:247-257

Jones DL, Dennis PG, Owen G, Hees PW (2003) Organic acid behavior in soil-misconceptions and knowledge gaps. Plant Soil 248:31-41

Jungk A (2002) Dynamics of nutrient movement at the soil-root interface. In: Dekker M (ed) Plant roots, the hidden half. pp 587-616, New York

Krzyszowska AJ, Blaylock MJ, Vance GF, David MB (1996) Ion-chromatographic analysis of low molecular weight organic acids in spodosol forest floor solutions. Soil Sci Soc Am J 60:1565-1571

Kuo S (1996) Phosphorus. In: Sparks DL (ed) Methods of soil analysis, Part 3: chemical methods. Soil Science Society of America. Madison, Wisc pp 869-919

Li MG, Shinano T, Tadano T (1997) Distribution of exudates of Lupin roots in the rhizosphere under phosphorus deficient conditions. Soil Sci Plant Nutr 43:237-245

Liang R, Li C (2003) Differences in cluster-root formation and carboxylate exudation in Lupinus albus L. under different nutrient deficiencies. Plant Soil 248:221-227

Marschner H (1995) Mineral nutrition of higher plants. Academic Press Harcourt Brace and Company, Publishers, London. $889 \mathrm{p}$

Morel C, Hinsinger P (1999) Root-induced modifications of the exchange of phosphate ion between soil solution and soil solid phase. Plant Soil 211:103-110 
Neumann G, Massonneau A, Langlade N, Dinkelaker B, Hengeler C, Römheld V, Martinoia E (2000) Physiological aspects of cluster root function and development in phosphorus-deficient White Lupin (Lupinus albus L.). Ann Bot 85:909-919

Neumann G, Massonneau A, Martinoia E, Römheld V (1999) Physiological adaptation to phosphorus deficiency during proteoid root development in white lupin. Planta 208:373-382

Puschenreiter M, Wenzel WW, Wieshammer G, Fitz WJ, Wieczorek S, Kanitsar K, Köllensperger G (2005) Novel micro-suction cup design for sampling soil solution at defined distances from roots. J Plant Nutr Soil Sci 168:386-391

Rais D, Nowack B, Schulin R, Luster J (2006) Sorption of trace metals by standard and micro suction cups in the absence and presence of dissolved organic carbon. J Environ Qual 35:50-60

Rozycki H, Strzelczyk E (1986) Free amino acids production by actinomycetes, isolated from soil, rhizosphere and mycorrhizosphere of pine (Pinus sylvestris L.). Zentralbl Mikrobiol 141:423-429

Ryan P, Delhaize E, Jones D (2001) Function and mechanism of organic anion exudation from plant roots. Ann Rev Plant Physiol Plant Mol Biol 52:527-560

Sandnes A, Eldhuset TD, Wollebaek G (2005) Organic acids in root exudates and soil solution of Norway spruce and silver birch. Soil Biol Biochem 37:259-269
Skene KR (2003) The evolution of physiology and development in the cluster root: teaching an old dog new tricks? Plant Soil 248:21-30

Strobel BW (2001) Influence of vegetation on low-molecular-weight carboxylic acids in soil solution-a review. Geoderma 99:169-198

Vetterlein D, Jahn R (2004) Gradients in soil solution composition between bulk soil and rhizosphere-In situ measurement with changing soil water content. Plant Soil 258:307-317

Vetterlein D, Marschner H (1993) Use of a microtensiometer technique to study hydraulic lift in a sandy soil planted with pearl millet (Pennisetum americanum [L.] Leeke). Plant Soil 149:275-282

Vetterlein D, Marschner H, Horn R (1993) Microtensiometer technique for in situ measurement of soil matric potential and root water extraction from sandy soil. Plant Soil 149:263-273

Wang ZY, Kelly JM, Kovar JL (2004) In situ dynamics of phosphorus in the rhizosphere solution of five species. J Environ Qual 33:1387-1392

Watt M, Evans JR (1999) Proteoid roots: physiology and development. Plant Physiol 121:317-323

Wolt J (1994) Soil solution chemistry: applications to environmental science and agriculture. John Wiley and Sons, New York 